$$
\text { CONF-950413--66 }
$$

Note: This is a preprint of a paper being submitted for publication. Contents of this paper should not be quoted nor referred to without permission of the author(s).

To appear in Spring 96 MRS Proceedings.

\title{
Microwave Annealing of Ion Implanted 6H-SiC
}

J. A. Gardner, M. V. Rao, and Y. L. Tian

George Mason University

Fairfax, VA

O. W. Holland

Oak Ridge National Laboratory

Oak Ridge, Tennessee

G. Kelner and J. A. Freitas, Jr.

Naval Research Laboratory

Washington, DC

\section{Ahmad}

FM Technologies Inc.

Fairfax, VA

\begin{abstract}
"The submitted manuscript has been authored by a contractor of the U.S. Government under contract No. DE-AC05-960R22464. Accordingly, the U.S. Government retains a nonexclusive, royalty-free license to publish or reproduce the published form of this contribution, or allow others to do so, for U.S. Government purposes."
\end{abstract}

Prepared by the

Oak Ridge National Laboratory

Oak Ridge, Tennessee 37831 managed by

LOCKHEED MARTIN ENERGY RESEARRCH CORP.

for the

U.S. DEPARTMENT OF ENERGY

under contract DE-AC05-96OR22464

May 1996

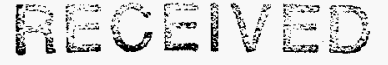




\section{DISCLAIMER}

Portions of this document may be illegible in electronic image products. Images are produced from the best available original document. 


\author{
J.A. GARDNER*, M.V. RAO*, Y.L. TIAN*, O.W. HOLLAND*", G. KELNER***, J.A. \\ FREITAS, $\mathrm{Jr}^{* * *}$ and I. AHMAD ${ }^{* \cdots *}$ \\ *ECE Department, George Mason University, Fairfax, Virginia 22030 \\ "* Oak Ridge National Laboratory, Oak Ridge, Tennessee, 37831 \\ *** Naval Research Laboratory, Washington, D.C. 20375 \\ **** FM Technologies Inc., Fairfax, Virginia, 22032
}

\title{
ABSTRACT
}

Microwave rapid thermal annealing has been utilized to remove the lattice damage caused by nitrogen $(\mathrm{N})$ ion-implantation as well as to activate the dopant in $6 \mathrm{H}-\mathrm{SiC}$. Samples were annealed at temperatures as high as $1400^{\circ} \mathrm{C}$, for $10 \mathrm{~min}$. Van der Pauw Hall measurements indicate an implant activation of $36 \%$, which is similar to the value obtained for the conventional furnace annealing at $1600^{\circ} \mathrm{C}$. Good lattice quality restoration was observed in the Rutherford backscattering and photoluminescence spectra.

\section{INTRODUCTION}

In the past several years $\mathrm{SiC}$ has received a great deal of attention for its potential use in semiconductor device applications. $\mathrm{SiC}$ has certain qualities that could make it extremely attractive for use in high-temperature and high-power integrated circuits [1]. The $\mathrm{SiC}$ devices could be used up to temperatures as high as $700^{\circ} \mathrm{C}$ provided that the packaging technology can withstand such an extreme environment. This material has the additional advantage of being chemically inert, which would allow the devices to be exposed to corrosive or similarly harsh environments without degradation. Another aspect of $\mathrm{SiC}$, is that the electron saturation velocity is about three times higher than that of $\mathrm{Si}[1]$. This would allow the device to operate at higher speeds, as far as switching logic is concerned. The higher speed of the device would also permit circuits to operate in a higher frequency range (i.e, microwave range) as compared to $\mathrm{Si}$. SiC has three main polytypes which are currently being used for discrete and integrated circuit fabrication. They consist of $3 \mathrm{C}$ (cubic), $4 \mathrm{H}$, and $6 \mathrm{H}$ (hexagonal). In this study we have used only $6 \mathrm{H}-\mathrm{SiC}$.

In fabricating planar $\mathrm{SiC}$ devices, it is necessary to use ion implantation as the vehicle for doping, using various impurities. Thermal diffusion techniques would be highly impractical since the diffusion coefficients of impurities in $\mathrm{SiC}$ are extremely low thereby requiring temperatures as high as $1800^{\circ} \mathrm{C}$ for long periods of time [1]. The sample would decompose at such a high temperature due to the thermal evaporation of Si. Ion implantation provides the user with the capability of selective area doping without the need of subjecting the material to extreme temperatures. However, during the process of implantation the crystal lattice of the $\mathrm{SiC}$ is damaged as the ions penetrate it. The damaged material must then be subjected to heating in order to restore the crystal lattice to its original structure. This process also has the effect of electrically activating the implants [2]. At present, the implanted $\mathrm{SiC}$ is annealed in ceramic processing furnaces at temperatures as high as $1650^{\circ} \mathrm{C}$ [3]. Because the conventional annealing process can take several hours due to slow ramp up and ramp down times, the possibility of using microwaves for rapid thermal processing has been explored. This helps to prevent redistribution of impurity atoms during annealing [4] 
Microwave energy can provide a fast and efficient method to high temperature anneal SiC, with the proper insulating material. Microwave energy can be directed and tuned, which will cause the material to heat up locally at an accelerated rate [5-8]. Rise rates of $300^{\circ} \mathrm{C} /$ min have been achieved, compared to $10^{\circ} \mathrm{C} / \mathrm{min}$; in the conventional annealing techniques. This process has the possibility of being scaled up so as to anneal arrays of wafers in the same short time period, (unlike halogen lamp RTP) which is one of the requirements for commercial application. The intention is to investigate this new technology by annealing $6 \mathrm{H}-\mathrm{SiC}$ samples which have been implanted with nitrogen. Electrical and lattice quality tests were performed on these samples in order to compare them with conventional annealing.

\section{EXPERIMENT}

The microwave annealing experiments were carried out in a $\mathrm{TE}_{103}$ single mode cavity with a variable power source of $1 \mathrm{~kW}$. In order to achieve maximum energy efficiency and heat the samples to a high temperature in a short ramp time, critical tuning and coupling was achieved and maintained during the entire annealing process by adjusting the position of a moving plunger and the size of an adjustable iris. A directional coupler was used to monitor the reflected power. The temperature of the samples was measured by a two-color pyrometer and controlled by manually varying the input power.

The samples used for the annealing tests were $\mathrm{N}$-implanted $\mathrm{p}$-type $6 \mathrm{H}$-SiC with a background carrier concentration of $\sim 10^{18} \mathrm{~cm}^{-3}$. The samples were placed in a $\mathrm{SiC}$ crucible, which acted as a susceptor for absorbing microwave power and heating the $6 \mathrm{H}-\mathrm{SiC}$ samples. In addition, the use of the $\mathrm{SiC}$ crucible protected the surface of the samples from pitting due to thermal dissociation caused by the evaporation of silicon. The crucible itself may also have some dissociation and hence maintained high Si partial pressure in the vicinity of the SiC sample during annealing. The SiC crucible was enclosed in an insulating material which minimized the heat loss from radiation and stabilized the temperature over the annealing cycle. Especially in the high temperature range of over $1300^{\circ} \mathrm{C}$, significant radiation loss would limit the maximum annealing temperature to be reached if the insulation were not used.

Arcing was one of the problems frequently encountered in the microwave annealing experiments. It was caused by an intense local electric field near a sharp corner or discontinuities of the crucible and insulation. A high and uncontrollable temperature caused by arcing could heat up the $\mathrm{SiC}$ samples to a temperature at which it would degrade and become useless for device fabrication. Therefore the geometry of the crucible and the insulation must be carefully designed to eliminate the arcing.

The sample was placed in the cavity and temperatures ranging from $1150^{\circ} \mathrm{C}$ to $1400^{\circ} \mathrm{C}$ were achieved in a few minutes. A typical temperature/time cycle obtained for $1230^{\circ} \mathrm{C}$ annealing is shown in Fig 1 . The temperature rose at a rate of $\sim 300^{\circ} \mathrm{C} / \mathrm{min}$ and falls at a rate of $\sim 200$ ${ }^{\circ} \mathrm{C} / \mathrm{min}$, which is monitored by an optical pyrometer through a narrow orifice in the insulating case. Various gas ambients were tried during the annealing process. Argon and helium gases resulted in arcing at relatively low temperatures whereas nitrogen could withstand at least 1450 ${ }^{\circ} \mathrm{C}$. The annealing was performed for a duration of 10-15 min after the temperature had been stabilized. After annealing, the samples were removed and subjected to a thorough cleaning process by solvents. A dip in HF is necessary to remove the nitride layer formed on the surface during annealing in the $\mathrm{N}_{2}$ ambient. Hall measurements, Rutherford Backscattering (RBS), and photoluminescence measurements were performed on the annealed samples in order to evaluate the electrical activation of the implant as well as the lattice perfection. 


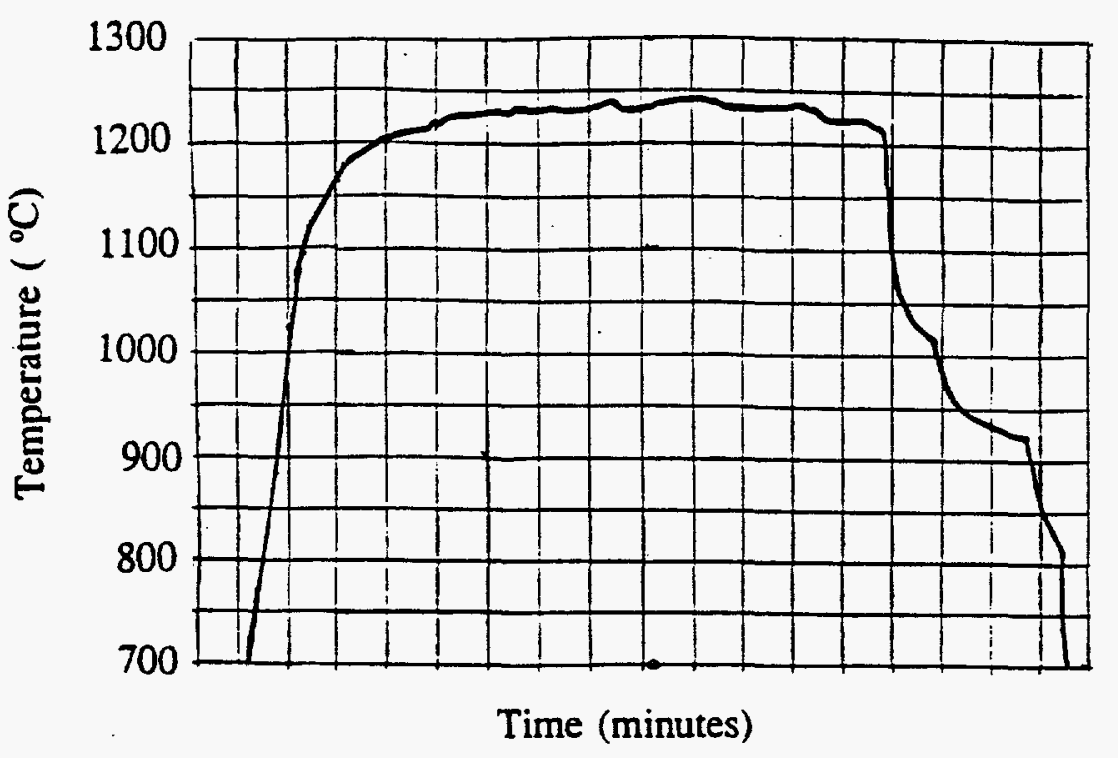

Fig.1. Typical temperature / time cycle of microwave annealing.

\section{RESULTS}

The $\mathrm{N}$-implants were done at $700^{\circ} \mathrm{C}$ down to a depth of $2.5 \mu \mathrm{m}$ using a multiple ion energy schedule. The nitrogen implant schedule used was $50 \mathrm{keV} / 6.1 \times 10^{13} \mathrm{~cm}^{-2}, 100 \mathrm{keV} /$ $9.2 \times 10^{13} \mathrm{~cm}^{-2}, 250 \mathrm{keV} / 1.4 \times 10^{14} \mathrm{~cm}^{-2}, 500 \mathrm{keV} / 1.6 \times 10^{14} \mathrm{~cm}^{-2}, 800 \mathrm{keV} / 1.9 \times 10^{14} \mathrm{~cm}^{-2}, 1 \mathrm{MeV} /$ $2.05 \times 10^{14} \mathrm{~cm}^{-2}, 2 \mathrm{MeV} / 2.2 \times 10^{14} \mathrm{~cm}^{-2}, 3 \mathrm{MeV} / 2.4 \times 10^{14} \mathrm{~cm}^{-2}$, and $4 \mathrm{MeV} / 2.67 \times 10^{14} \mathrm{~cm}^{-2}$ in order to obtain a uniform nitrogen concentration of $10^{19} \mathrm{~cm}^{-3}$. The as-implanted material is dark/opaque in color due to the lattice damage. Once annealed the samples regained their transparency with increasing annealing temperatures. No deterioration was observed in the surface morphology after annealing at $1400{ }^{\circ} \mathrm{C}$.

The lattice perfection of the as-implanted and annealed samples was evaluated by performing RBS via channeling measurements. A $2.3 \mathrm{MeV} \mathrm{He}^{++}$beam was used along with a standard solid-state detector which was positioned to record backscattered ions at $160^{\circ}$. Recorded spectra are shown in Fig. 2. Spectra from an aligned and randomly oriented virgin sample are also given in Fig. 2 to use as a basis for comparison with the RBS data. As shown in Fig. 2 the yield in the as-implanted sample is closer to the virgin level than to the random level. This random level indicates the scattering from a completely amorphized material. The low yield of the as-implanted sample is due to the implantation at an elevated temperature of $700{ }^{\circ} \mathrm{C}$. Accumulated lattice damage is less at elevated implant temperatures due to dynamic selfannealing. This is in contrast to the room temperature implantation in which the as-implant yield would be at the random level [3]. After annealing at $1140^{\circ} \mathrm{C}$ there is a significant reduction in the scattering yield, bringing the spectra closer to the virgin level. Nearly identical spectra were obtained for 1230 and $1320^{\circ} \mathrm{C}$ anneals. For $1400^{\circ} \mathrm{C}$ annealing, the spectra coincide with the virgin level indicating highly effective lattice damage removal. Similar RBS spectra were obtained on the samples annealed at 1500 and $1600{ }^{\circ} \mathrm{C}$ in the conventional Brew ceramic processing furnace. 


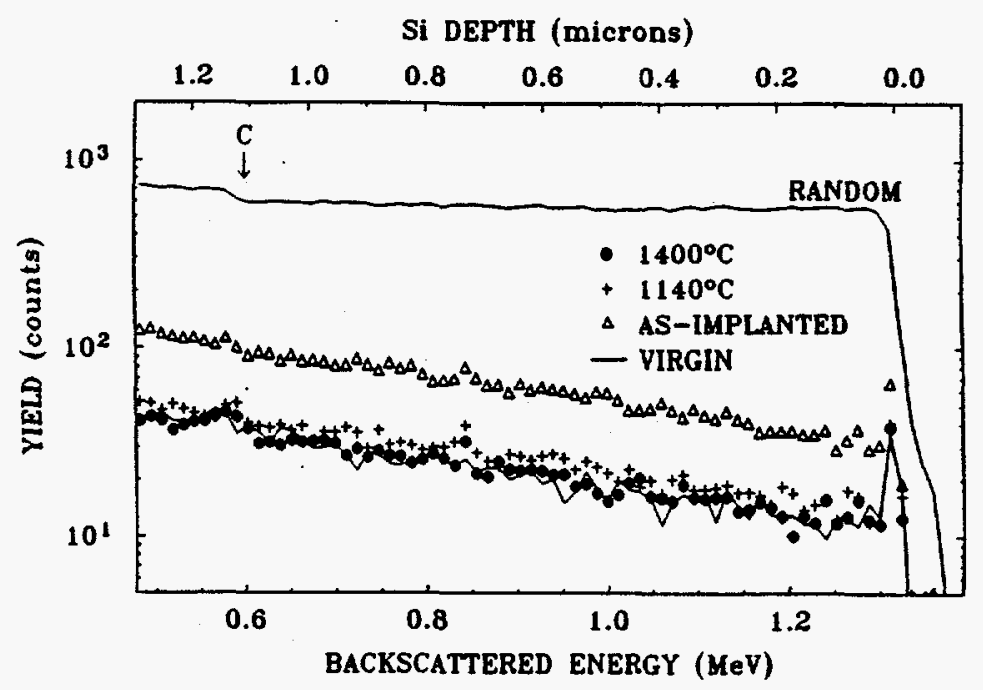

Fig. 2. RBS spectra on $\mathrm{N}$-implanted $\mathrm{SiC}$ before and after annealing.'

The electrical characteristics of the annealed material were evaluated by performing van der Pauw Hall measurements at room temperature. We were unable to perform Hall measurements on samples annealed at temperatures less than $1400^{\circ} \mathrm{C}$. This is due to the high resistance of the material associated with the residual implant damage. We observed a high resistance behavior in $\mathrm{SiC}$ bombarded with $\mathrm{Si}$ or $\mathrm{C}$ at levels which produce a high concentration of point defects. RBS provides a qualitative measure of gross lattice damage, which is in the form of extended defects like dislocation loops. Though the concentration of the extended defects is reduced at temperatures below $1400^{\circ} \mathrm{C}$, a large concentration of point defects, which cannot be detected by RBS, may still exist.

For the sample annealed at $1400^{\circ} \mathrm{C}$ we measured a sheet resistance of $3 \times 10^{2} \Omega / \square$, a sheet carrier concentration of $5.6 \times 10^{14} \mathrm{~cm}^{-2}$, and a carrier mobility of $37 \mathrm{~cm}^{2} / \mathrm{V} . \mathrm{s}$. The percent activation, which is obtained from the ratio of sheet carrier concentration and the total implant dose of $1.57 \times 10^{15} \mathrm{~cm}^{-2}$, was found to be approximately $36 \%$. This activation is comparable to the values obtained [3] for conventional $1600^{\circ} \mathrm{C}$ annealing. However the carrier mobility measured for $1400^{\circ} \mathrm{C}$ microwave annealing is less than the value of $50 \mathrm{~cm}^{2} / \mathrm{V}$.s obtained for the $1600{ }^{\circ} \mathrm{C}$ conventional annealing.

Photoluminescence measurements have also been taken in order to obtain addition information on the lattice quality of the sample as well as pair recombination information. Figure 3 shows the low temperature and low resolution photoluminescence (PL) spectrum of a $\mathrm{p}$ type substrate, which has been implanted with $\mathrm{N}$ and microwave annealed at $1400^{\circ} \mathrm{C}$ for $10 \mathrm{~min}$. Also represented in the figure is the PL spectrum of the back-surface of the sample (un-implanted surface). The sharp lines observed in the spectral range between 3.0 and $2.8 \mathrm{eV}$, not clearly visible in the low resolution spectra shown in Fig. 3, are assigned to recombination processes involving the distribution of close $\mathrm{N}$-donor and $\mathrm{Al}$-acceptor pairs (close $\mathrm{DAP}$ recombination) present in the substrate. The broad shoulders detected between 2.85 and $2.65 \mathrm{eV}$ are the zero 


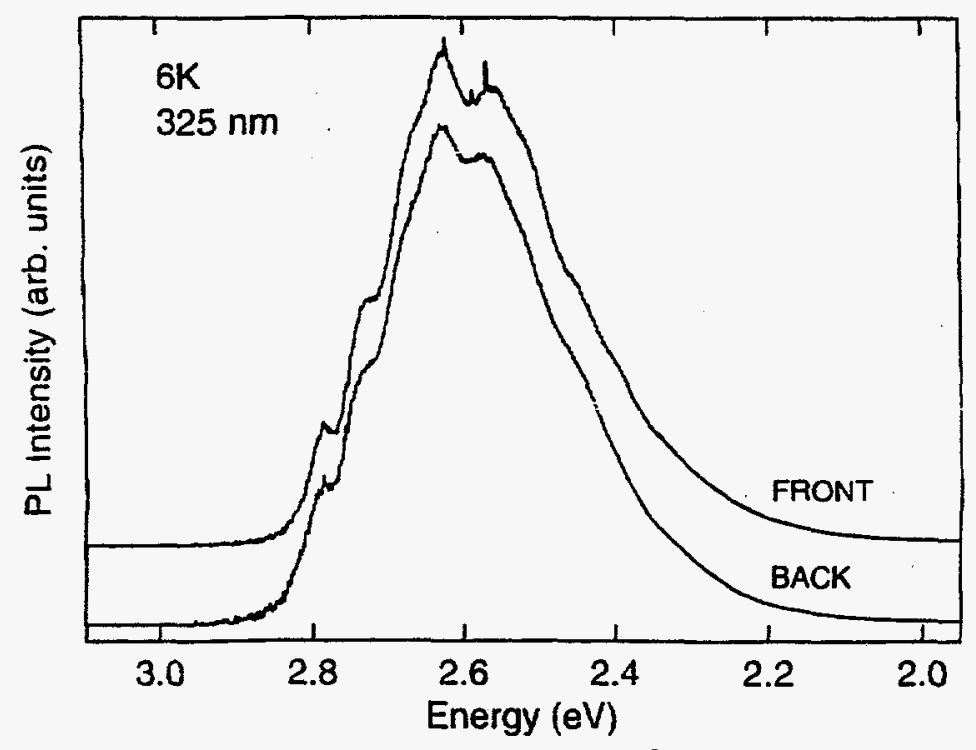

Fig. 3. Photoluminescence spectrum in implanted (front) and un-implanted (back) $6 \mathrm{H}-\mathrm{SiC}$.

phonon lines (ZPL) associated with the recombination of distant N-Al DAP. The only difference observed between the two spectra are the weak sharp lines at $2.623 \mathrm{eV}, 2.588 \mathrm{eV}$, and $2.586 \mathrm{eV}$ in the implanted sample. These lines are associated with defects induced by the ion implantation [9]. The relatively small intensity of these lines and the similarity between both spectra, suggested that the annealing treatment has recovered the crystalline quality of the substrate. Although the transport measurements performed on such layers shows conclusive evidence of $\mathrm{N}$ activation, we were not able to observe any emission band which could undoubtedly be assigned to the implanted $\mathrm{N}$ species. Since the penetration depth of the laser-line is much larger than the implanted layer thickness, we are planning to repeat this experiment with a high absorbing light source.

\section{CONCLUSIONS}

Microwave annealing seems to be an attractive method for rapid thermal annealing of implanted $\mathrm{SiC}$. The electrical characteristics and lattice perfection of the annealed material are comparable to the values obtained for conventional ceramic processing furnace anneals.

\section{ACKNOWLEDGMENT}

The work at George Mason University is supported by NSF under Grant \#ECS-9319885, and Oak Ridge National Laboratory, managed by Lockheed Martin Energy Research Corp for the U.S. Department of Energy, under contract number DE-AC05-96OR22464. We also wish to give special thanks to Ilene S. Manster for her assistance in editing this report.

\section{DISCLAIMER}

This report was prepared as an account of work sponsored by an agency of the United States Government. Neither the United States Government nor any agency thereof, nor any of their employees, makes any warranty, express or implied, or assumes any legal liability or responsibility for the accuracy, completeness, or usefulness of any information, apparatus, product, or process disclosed, or represents that its use would not infringe privately owned rights. Reference herein to any specific commercial product, process, or service by trade name, trademark, manufacturer, or otherwise does not necessarily constitute or imply its endorsement, recommendation, or favoring by the United States Government or any agency thereof. The views and opinions of authors expressed herein do not necessarily state or reflect those of the United States Government or any agency thereof. 


\section{REFERENCES}

1. R.F. Davis, G. Kelner, M. Shur, J.W. Palmour, and J.A. Edmond, proc. IEEE 79, p.677 (1991).

2. S.K. Ghandhi, VLSI Fabrication Principles, John Wiley, New York, 1994, pp. 368-406.

3. J. Gardner, M.V. Rao, O.W. Holland, G. Kelner, D.S. Simons, P.H. Chi, J.M. Andrews, J. Kretchmer and M. Ghezzo, J. Electron. Mater. 25, May 1996 issue and the references therein.

4. M. R. Splinter, R. F. Palys, and M. M. Beguwala, Low Temperature Microwave Annealing of Semiconductor Devices, United States Patent, \# 4,303,455, Dec. 1, 1981.

5. P. D. Scovell, Method of Reactivating Implanted Dopants and Oxidation Semiconductor Wafers by Microwaves, United States Patent \# 4,490,183, Dec. 25,1984.

6. S.L. Zhang, R. Buchta, and D. Sigurd, Thin Solid Films 246, p. 151 (1994).

7. T. Fukano, T. Ito, and H. Ishikawa, Microwave Annealing for Low Temperature VLSI processing, IEDM Tech. Digest, p. 224 (1985).

8. H. Amada, Method and Apparatus for Microwave Heat-Treatment of a Semiconductor Wafer, United States Patent \# 4,667,076, May 19, 1987.

9. M.V. Rao, P. Griffiths, O.W. Holland, G. Kelner, J.A. Freitas, Jr., D.S. Simons, P.H. Chi, and M. Ghezzo, J. Appl. Phys. 77, p. 2479 (1995). 